\title{
Pancreatic ascites: complication after endoscopic ultrasound-guided fine needle aspiration of a pancreatic cyst
}

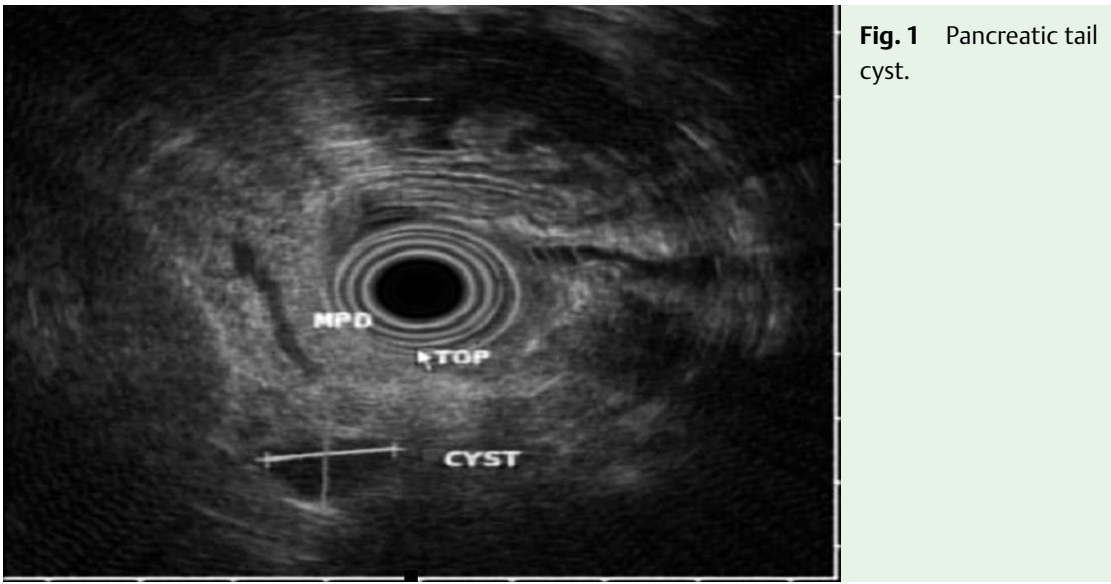

Pancreatic ascites can result from disruption of the pancreatic duct with the resultant intraperitoneal accumulation of pancreatic juice. A 71-year-old female was admitted to our hospital with complaints of diffuse, sharp abdominal pain for the last 7 days. One week prior to admission she had undergone an endoscopic ultrasound-guided fine needle aspiration (EUS-FNA) of a pancreatic tail cyst; a 22gauge needle was used to aspirate clear fluid from what appeared to be a 13- $\mathrm{mm}$ side branch intraductal papillary mucinous neoplasm ( $\bullet$ Fig. 1).

Upon presentation her abdomen was diffusely tender with no rebound or guarding. A computed tomography (CT) scan of the abdomen revealed a loculated collection in her left upper abdomen measuring $10 \mathrm{~cm} \times 4.7 \mathrm{~cm}$, inflammatory changes around the pancreas consistent with acute pancreatitis, and pancreatic duct dilation ( $\bullet$ Fig. 2).

A drain placed via CT guidance produced serosanguineous fluid, and the amylase level was $7809 \mathrm{U} / \mathrm{L}$. The patient subsequently underwent an endoscopic retrograde cholangiopancreatography (ERCP) for pancreatic duct stenting. At the time of the ERCP an ampullary adenoma was biopsied, which revealed a tubular-villous adenoma with high-grade dysplasia (๑ Fig. 3).

The pancreatic collection progressively resolved over a period of 4-6 weeks, following treatment with pancreatic duct

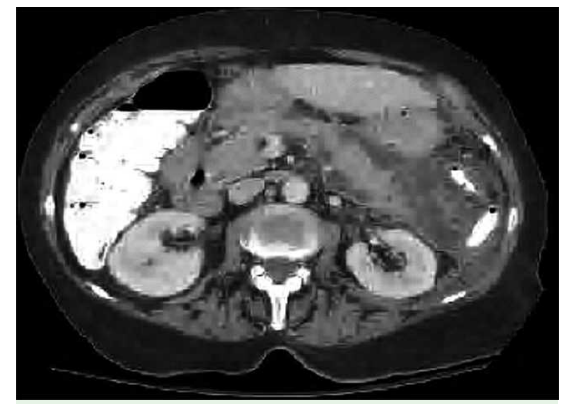

Fig. 2 Loculated collection on computed tomography.

our FNA "track" passing through the main pancreatic duct allowed for decompression causing pancreatic ascites. The endoscopic placement of a transpapillary pancreatic duct stent could facilitate healing of ductal disruptions by partially occluding the leaking duct or bypassing the pancreatic sphincter, converting the normally high-pressure pancreatic ducts to a low-pressure system with preferential flow through the stent [3].

Endoscopy_UCTN_Code_CPL_1AL_2AF

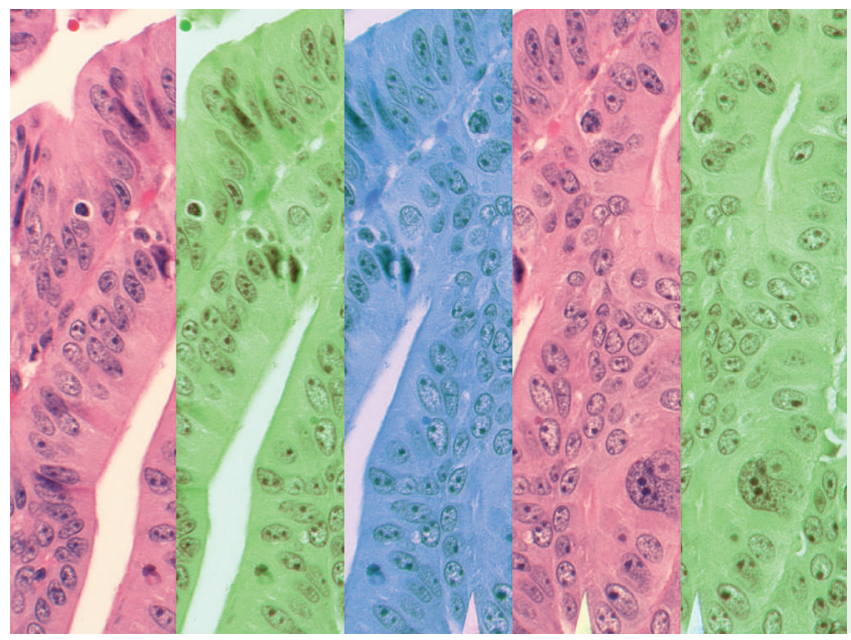

Fig. 3 Tubular-villous adenoma with highgrade dysplasia. 


\section{J. P. Babich', R. J. Bonasera', J. Klein²,} D. M. Friedel ${ }^{1}$

1 Division of Gastroenterology, Hepatology, and Nutrition, Winthrop University Hospital, Mineola, New York, USA

2 Department of Pathology, Winthrop University Hospital, Mineola, New York, USA

\section{References}

1 Al-Haddad M, Wallace M, Woodward S et al. The safety of fine needle aspiration guided by endoscopic ultrasound: a prospective study. Endoscopy 2007; 40: 204-208

2 Singh P, Gelrud A, Schmulewitz N, Chauhan S. Hemosuccus pancreaticus after EUS-FNA of pancreatic cyst. Gastrointest Endosc 2008; 67: 543

3 Carr-Locke DL, Gregg JA. Endoscopic manometry of pancreatic and biliary sphincter zones in man: basal results in healthy volunteers. Dig Dis Sci 1981; 26: 7-15

\section{Bibliography}

DOI $10.1055 / \mathrm{s}-0029-1214479$

Endoscopy 2009; 41: E211-E212

(c) Georg Thieme Verlag KG Stuttgart · New York . ISSN 0013-726X

\section{Corresponding author}

\section{J. P. Babich MD}

Division of Gastroenterology, Hepatology, and Nutrition

Winthrop University Hospital

222 Station Plaza North Suite 429

Mineola

New York 11501

USA

Fax: +1-516-663-4617

jpbabich@aol.com 